\title{
Simulated Atlantic Multidecadal Oscillation during the Holocene
}

\author{
WEI WEI AND GERRIT LOHMANN \\ Alfred Wegener Institute for Polar and Marine Research, Bremerhaven, Germany
}

(Manuscript received 16 November 2011, in final form 3 April 2012)

\begin{abstract}
The Atlantic multidecadal oscillation (AMO) and its possible change during the Holocene are examined in this study, using long-term simulations of the earth system model Community Earth System Models (COSMOS). A quasi-persistent $\sim 55-80$-yr cycle characterizing in the North Atlantic sea surface temperature is highly associated with the multidecadal variability of the Atlantic meridional overturning circulation (AMOC) during the Holocene. This mode can be found throughout the Holocene, indicating that the AMO is dominated by internal climate variability. Stronger-than-normal AMOC results in warmer-than-normal surface temperature spreading over almost the whole North Hemisphere, in particular the North Atlantic Ocean. During the warm phase of the AMO, more precipitation is detected in the North Atlantic low and high latitudes. It also generates a dipolar seesaw pattern in the sea ice anomaly. The results reveal that the influence of the AMO can be amplified by a more vigorous AMOC variability during the early Holocene in the presence of a remnant of the Laurentide Ice Sheet and when freshwater entered the North Atlantic Ocean. This conclusion could have potential application for the past AMO reconstruction and the future AMO estimation.
\end{abstract}

\section{Introduction}

The Atlantic multidecadal oscillation (AMO) has been considered a dominant mode of variability in the North Atlantic sea surface temperature (SST) with a duration of 55-80 yr. It was first detected in the instrumental data (Schlesinger and Ramankutty 1994; Kerr 2000) and later on proved to exist in both proxy (Mann et al. 1995; Lohmann et al. 2004; Grosfeld et al. 2007; Hetzinger et al. 2008; Poore et al. 2009; Knudsen et al. 2011) and climate models (Delworth and Mann 2000; Latif et al. 2004; Knight et al. 2005).

The typical feature of the AMO is that during its warm (cold) phase, the North Atlantic Ocean experiences a general warming (cooling) in the amplitude of about $0.2^{\circ} \mathrm{C}$ (e.g., Enfield et al. 2001). Previous studies have demonstrated that this basinwide pattern has a large influence on almost the whole North Hemisphere climate, for example, Atlantic hurricanes (Goldenberg et al. 2001; Knight et al. 2006; Zhang and Delworth 2006), India/Sahel rainfall (Folland et al. 1986; Rowell

Corresponding author address: Wei Wei, Alfred Wegener Institute for Polar and Marine Research, Bussestraße 24, 27570 Bremerhaven, Germany.

E-mail: wei.wei@awi.de et al. 1995; Knight et al. 2006), North American climate (Enfield et al. 2001; McCabe et al. 2004; Hu and Feng 2008; Feng et al. 2011), Arctic temperature (Chylek et al. 2009), North Pacific climate (Zhang and Delworth 2007), Asian monsoon (Lu et al. 2006), and even part of the South Hemisphere, for example, northeastern Brazil rainfall (Folland et al. 2001; Knight et al. 2006). Consequently, understanding and predicting the AMO is highly important for all of society, especially in the undergoing anthropogenic-induced global warming conditions, which may be masked by the AMO signal (Latif et al. 2004). A more recent study based on observation (Wang and Dong 2010) has revealed that the AMO and global warming have an equal contribution to the basinwide warming in the North Atlantic Ocean. This basinwide warming, in turn, could contribute to global warming via the AMOC change and the associated atmospheric $\mathrm{CO}_{2}$ increase.

Some attempts have been made to forecast the AMO in the next decades (Latif et al. 2004; Knight et al. 2005). However, because of the relatively short length of the instrumental data, there are still many uncertainties concerning its persistence and forcing mechanism, which makes any prediction more difficult. Thus, proxy data and modeling studies provide us with a complementary approach. Previous studies based on proxy data can date 
TABLE 1. Boundary conditions used in each simulation.

\begin{tabular}{|c|c|c|c|c|c|c|c|}
\hline \multirow[b]{3}{*}{ Experiment } & \multicolumn{6}{|c|}{ Boundary conditions } & \multirow[b]{3}{*}{ Integration time* (a) } \\
\hline & \multirow[b]{2}{*}{ Orbital } & \multicolumn{3}{|c|}{ Greenhouse gases } & \multirow[b]{2}{*}{ Topography } & \multirow[b]{2}{*}{ Melt flux (Sv) } & \\
\hline & & $\mathrm{CO}_{2}(\mathrm{ppm})$ & $\mathrm{CH}_{4}(\mathrm{ppb})$ & $\mathrm{N}_{2} \mathrm{O}(\mathrm{ppb})$ & & & \\
\hline CTL & Present & 280 & 760 & 270 & Present & 0 & $3500(1000)$ \\
\hline H6K & $6 \mathrm{ka} \mathrm{BP}$ & & 650 & & & & $3000(1000)$ \\
\hline $\mathrm{H} 9 \mathrm{KO}$ & $9 \mathrm{ka} \mathrm{BP}$ & 265 & 700 & 245 & Present & 0 & $3500(1000)$ \\
\hline H9KT & & & & & $9 \mathrm{ka} \mathrm{BP}$ & & $3000(1000)$ \\
\hline H9KM & & & & & & 0.09 & $1500(300)$ \\
\hline
\end{tabular}

* Total integration time with spinup time in the bracket.

back to the Holocene, an epoch during which orbital change, greenhouse gases (GHGs), solar forcing, and volcanic activities control the climate evolution. Knudsen et al. (2011) applied the spectral analyses to several high-resolution records from the region bounding the North Atlantic Ocean, and they found that a quasi-persistent 55-70-yr cycle existed through large parts of the last $8000 \mathrm{yr}$. Based on proxy SST records, Feng et al. (2009) pointed out that the centennial variability of the North Atlantic SST during the Holocene resembled the common AMO feature. More recently, Giry et al. (2012) showed that a substantial AMO-like signature can be found in their midHolocene coral records from the Caribbean, which have been used to reconstruct the temperature variation associated with the AMO (Heslop and Paul 2010). More efforts have been made concerning the reconstruction of the AMO for the last several centuries (e.g., Mann et al. 1995; Gray et al. 2004; Hetzinger et al. 2008).

Several modeling studies have been carried out in the direction of understanding the forcing mechanisms of the AMO and its climate influence (e.g., Delworth and Mann 2000; Latif et al. 2004; Knight et al. 2005; Knight et al. 2006). However, only few modeling studies (e.g., Oglesby et al. 2011) focus on the past AMO reconstruction. In this study, we investigate the AMO pattern and its robust feature during the Holocene by performing several numerical experiments. Moreover, comparisons between experiments allow us to explore the AMO variation during the Holocene, resulting from different external forcing. We also show the climate influence of the AMO under different climate background conditions, which might provide useful information for the future AMO dynamics.

\section{Model description and experiment setup}

In this study, we use the earth system model Community Earth System Models (COSMOS) developed by the
Max Planck Institute for Meteorology. The atmospheric component is the spectral atmosphere model ECHAM5 (Roeckner et al. 2003) with the resolution of T31, corresponding to $3.75^{\circ} \times 3.75^{\circ}$ in the horizontal, and 19 hybrid sigma-pressure levels in the vertical. The land processes are integrated into the atmosphere model using the land surface model Jena Scheme for BiosphereAtmosphere Coupling in Hamburg (JSBACH) (Raddatz et al. 2007) except for river routing, for which the hydrological discharge model is responsible (Hagemann and Dümenil 1997; Hagemann and Gates 2003). The ocean-sea ice component is the ocean general circulation model Max Planck Institute Ocean Model (MPIOM) (Marsland et al. 2003) with the resolution of GR30 in the horizontal and 40 unevenly spaced vertical levels, which includes the dynamics of sea ice formulated using viscous-plastic rheology (Hibler 1979). An orthogonal curvilinear grid allows for an arbitrary placement of the grid poles in the ocean model. In our setup, the North Pole is shifted to Greenland and the South Pole to the center of the Antarctic continent. The effect of mixing by advection with the unresolved mesoscale eddies is parameterized after Gent et al. (1995). No ice sheet model is included in this setup, that is, ice sheets are prescribed. Coupling between the atmosphere and the ocean components is done by the Ocean Atmosphere Sea Ice Soil, version 3 (OASIS3) coupler (Valcke 2006).

Several long-term timeslice experiments are performed: a preindustrial control experiment, CTL; a midHolocene one, H6K (i.e., $6 \mathrm{~kg}$ yr before A.D. 1950, short for $6 \mathrm{ka} \mathrm{BP}$ ); and three different early Holocene runs (H9KO, H9KT, and H9KM; i.e., $9 \mathrm{~kg}$ yr before A.D. 1950, short for $9 \mathrm{ka} \mathrm{BP}$ ), by prescribing the appropriate boundary conditions (Table 1). Orbital parameters are calculated according to Berger (1978). In the CTL and H6K experiments, the GHGs are prescribed according to the Paleoclimate Modelling Intercomparison Project (PMIP) (Crucifix et al. 2005). For the early Holocene experiments, the GHGs are taken from the ice core measurement (Indermühle et al. 1999; Brook et al. 2000; 
Sowers et al. 2003). In H9KO, the topography is kept the same as the CTL and H6K, whereas the H9KT and H9KM experiments use the topography at $9 \mathrm{ka} \mathrm{BP}$ based on reconstruction from the ice sheet model ICE-5G (VM2) (Peltier 2004), which includes the prescribed Laurentide Ice Sheet (LIS) (Fig. 1) and its feedback, for example, albedo, elevation, and vegetation. This changed topography results in the global averaged sea level height decreasing by about $30 \mathrm{~m}$ in these two setups. In the H9KM experiment, we additionally prescribe a freshwater forcing for a LIS background melt flux by adding $0.09 \mathrm{~Sv}\left(1 \mathrm{~Sv} \equiv 1 \times 10^{6} \mathrm{~m}^{3} \mathrm{~s}^{-1}\right)$ freshwater into the North Atlantic Ocean between $40^{\circ}$ and $60^{\circ} \mathrm{N}$ (Licciardi et al. 1999). These three early Holocene experiments enable us to distinguish the climate impact of the LIS and its melting.

For all the runs except H9KM, the atmospheric model is initialized by the mean climatology from an Atmospheric Model Intercomparison Project (AMIP)style experiment, which is performed using observed monthly sea surface temperatures and sea ice cover for the period 1978-99 (Roeckner et al. 2004). The ocean model is initialized using the Ocean Model Intercomparison Project (OMIP) forcing, which is derived from the European Centre for Medium-Range Weather Forecasts (ECMWF) reanalysis dataset (Gibson et al. 1999). The H9KM experiment starts from the $2000 \mathrm{yr}$ of the H9KT experiment. Integration time of each experiment can be seen in Table 1. For the statistical analysis used in this study, only the integration periods after the spinup are taken into account. Once the runs are initiated, no changes are permitted to the forcing. Consequently, all the simulated climatic fluctuations are generated by internal climate variability in the coupled system.

\section{Results}

\section{a. Large-scale feature of mean climate}

The seasonal and annual mean climatology is calculated by averaging the corresponding parameters over the whole valid integration periods.

The simulated surface air temperatures are shown in Fig. 2. Compared to the preindustrial condition, the most intriguing large-scale feature during the midHolocene is that the North Hemisphere high latitudes experience a warming up to $2^{\circ} \mathrm{C}$ in boreal summer, especially over the continents (Fig. 2a). It is attributed mainly to increased insolation in boreal summer, which is induced by a larger tilt of the orbital plane (Berger 1978), consistent with previous modeling studies (e.g., Braconnot et al. 2007). This effect is amplified during the early Holocene, resulting in a stronger summer

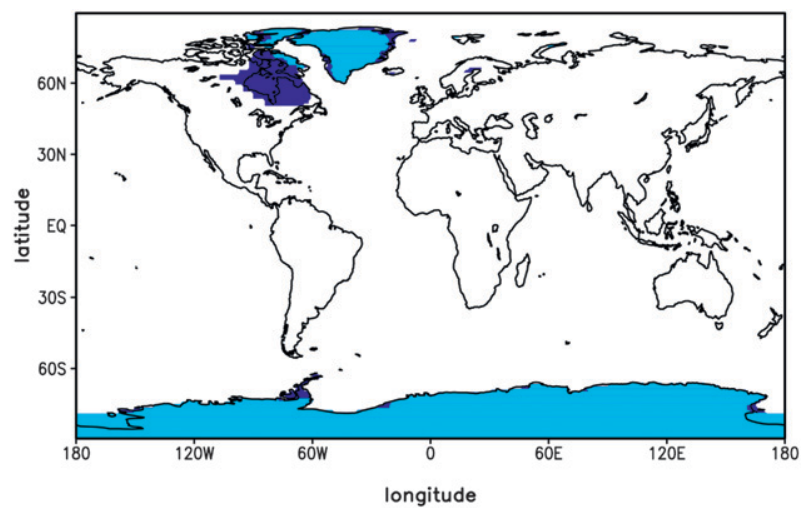

FIG. 1. Ice sheet coverage used in the simulation. Light blue represents the ice sheet coverage in the present-day condition; dark blue is the ice sheet coverage anomaly in $9 \mathrm{ka} \mathrm{BP}$, prescribed in experiments H9KT and H9KM.

warming in the North Hemisphere (Fig. 2b). Meanwhile, the winter cooling during the early Holocene is more pronounced than that during the mid-Holocene (Figs. 2a,b). Together with the cooling effect generated by less greenhouse gases, more cooling is seen in the annual mean values (Fig. 2b). Changes in the topography during the early Holocene have a considerable global influence. Compared with $\mathrm{H} 9 \mathrm{KO}$, a general warming due to the sea level change can be clearly seen in H9KT (Figs. 2b,c). Notably, there is a strong cooling (more than $10^{\circ} \mathrm{C}$ ) directly over the LIS (Fig. 2c) due to the combined effect of higher surface elevation and surface albedo. This cooling overcompensates the positive insolation anomaly and can extend to the northern part of the North Atlantic Ocean. The background melting of the LIS contributes additional cooling over the North Atlantic Ocean, which leads to up to $5^{\circ} \mathrm{C}$ over this area as well as Scandinavia (Fig. 2d).

Corresponding to the insolation change during the Holocene, the precipitation pattern is characterized by wetter conditions over Africa and India in both 6 and 9 ka BP (Figs. 3a-d). This increase in precipitation results from the ocean feedback on the increased summer insolation and has been found to be a key feature during the Holocene climate evolution (Kutzbach and Liu 1997; Zhao et al. 2005). This feature is further interpreted to be mainly caused by zonal moisture transport change during the last interglacial (Herold and Lohmann 2009). Over the tropical Atlantic, the enhanced land-sea contrast favors a northward shift of the intertropical convergence zone (ITCZ), which has been recorded in the proxy data (Haug et al. 2001). Over the tropical Pacific Ocean, a dipole anomaly exists along both the northern ITCZ and the South Pacific convergence zone (SPCZ). The former is mainly triggered by the cooling along the equator and the warming 
(a)

\section{December-February (DJF) June-August (JJA)}

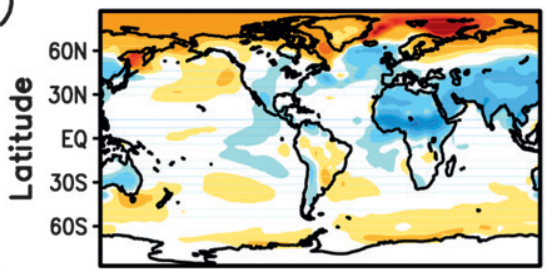

(b)

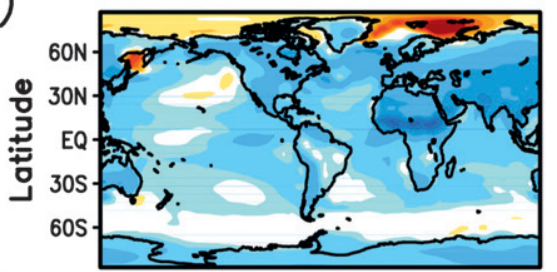

(c)

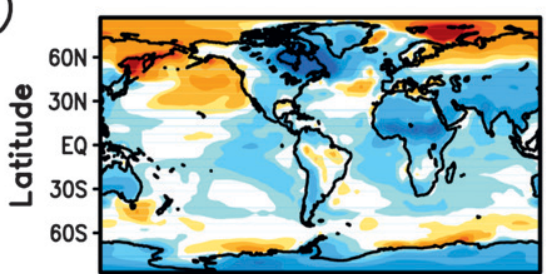

(d)
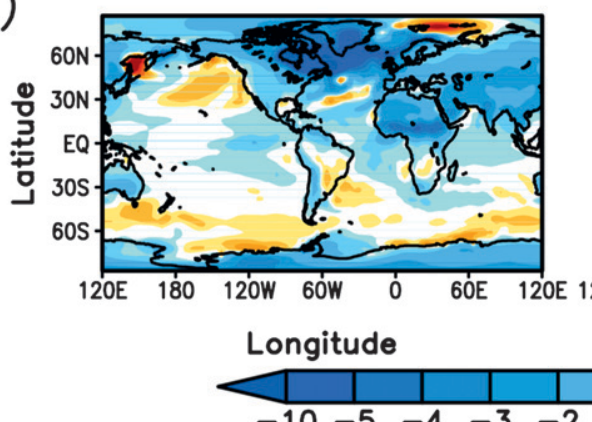
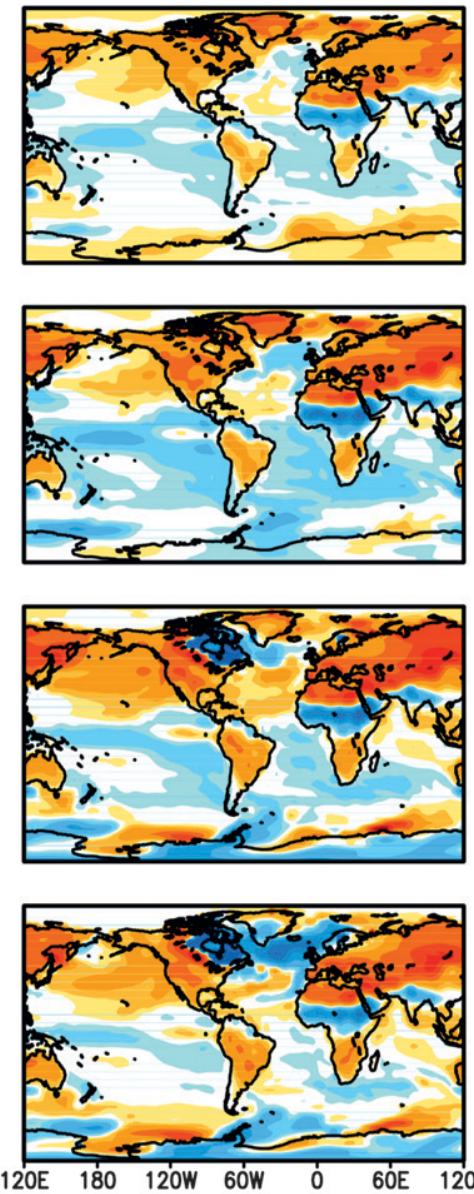

Longitude
Annual
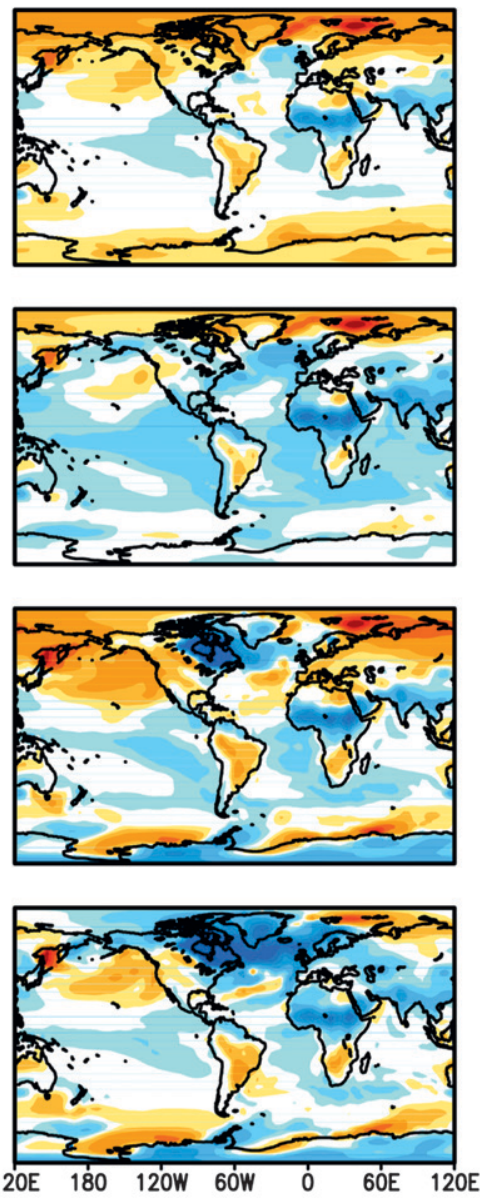

Longitude

FIG. 2. Simulated SST anomalies $\left({ }^{\circ} \mathrm{C}\right.$ ) relative to CTL in (a) H6K, (b) H9KO, (c) H9KT, and (d) H9KM for (left) boreal winter (December-February), (middle) boreal summer (June-August), and (right) annual mean.

over the midlatitude (Fig. 2) in response to the insolation change, which favors a northward displacement of the ITCZ (e.g., Koutavas et al. 2006).

The simulated Atlantic meridional overturning circulation (AMOC) streamfunction for the present condition has the maximum of $16.1 \mathrm{~Sv}$ at $1000-\mathrm{m}$ depth of $30^{\circ} \mathrm{N}$ (Fig. 4a), consistent with the estimates of global circulation from the hydrographic data $(15 \pm 2 \mathrm{~Sv}$; Ganachaud and Wunsch 2000). This value decreases by $2.3 \mathrm{~Sv}$ in the mid-Holocene and 3.3 Sv in the early Holocene run H9KO (Figs. 4b,c). A study by Fischer and Jungclaus (2009) using a similar model setup showed that this reduction of the North Atlantic Deep Water (NADW) formation also occurs in their mid-Holocene and Eemain experiments, when the North Hemisphere high latitudes get more insolation compared to the preindustrial condition. It can be explained by a combined effect of insolation-induced warming over the high latitudes and sea ice reduction in the Arctic. In experiment H9KT, the AMOC shows a very different feature with that in $\mathrm{H} 9 \mathrm{KO}$, with more than a 3-Sv increase at $40^{\circ} \mathrm{N}$ relative to CTL and a $6-\mathrm{Sv}$ increase relative to H9KO (Fig. 4d). The cooling effect of the LIS over the North Atlantic increases the surface water density and thus produces enhanced deep water formation, which can overwhelm the warming effect by the orbital change. This cooling is most significant over $40^{\circ}$ $60^{\circ} \mathrm{N}$. As a consequence, the deep-water formation increases dramatically in the same latitude band, leading to a shift of the AMOC maximum from $30^{\circ}$ to $40^{\circ} \mathrm{N}$ 
(a)

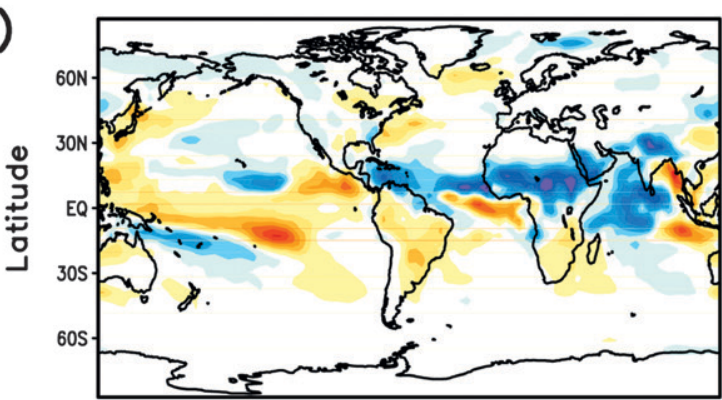

(b)

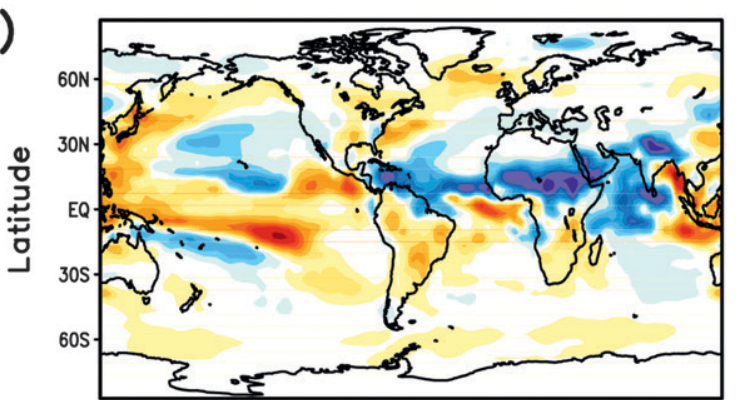

(c)

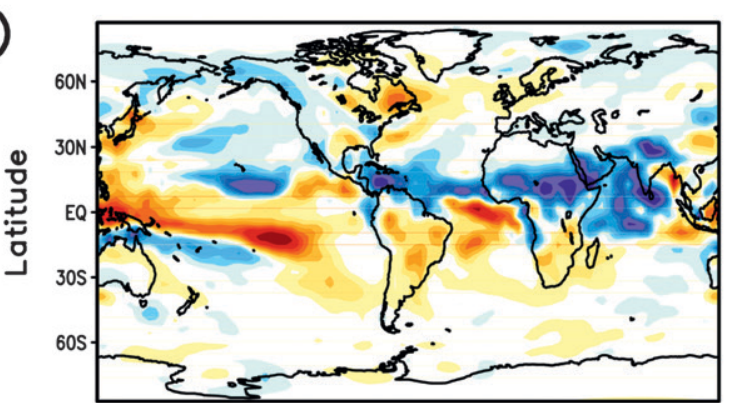

(d)

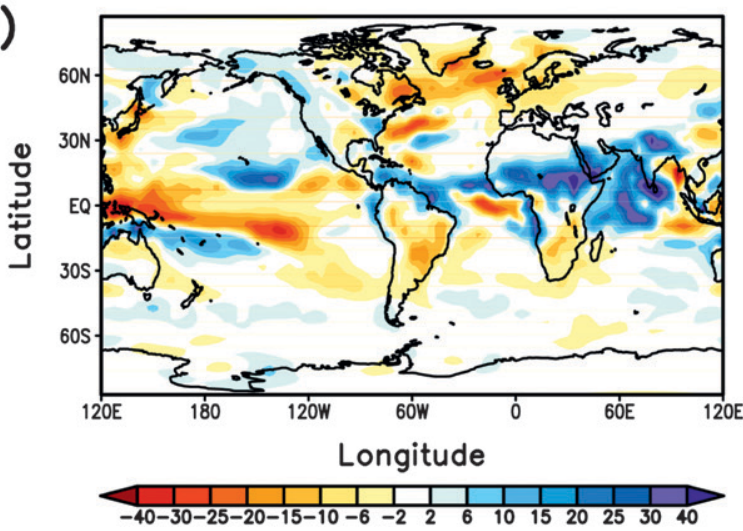

FIG. 3. Annual precipitation anomalies $\left(\mathrm{mm} \mathrm{month}^{-1}\right)$ relative to CTL in (a) H6K, (b) H9KO, (c) H9KT, and (d) H9KM.

(Fig. 4d). Contrary to the cooling effect by the ice sheet, the melting of the LIS injects large amounts of freshwater into the North Atlantic and triggers a strong reduction of the NADW formation. The magnitude of this reduction ( $\sim 6 \mathrm{~Sv}$; Fig. $4 \mathrm{e})$ is comparable to that in a Holocene transient run with identical forcing (Renssen et al. 2010) except that in
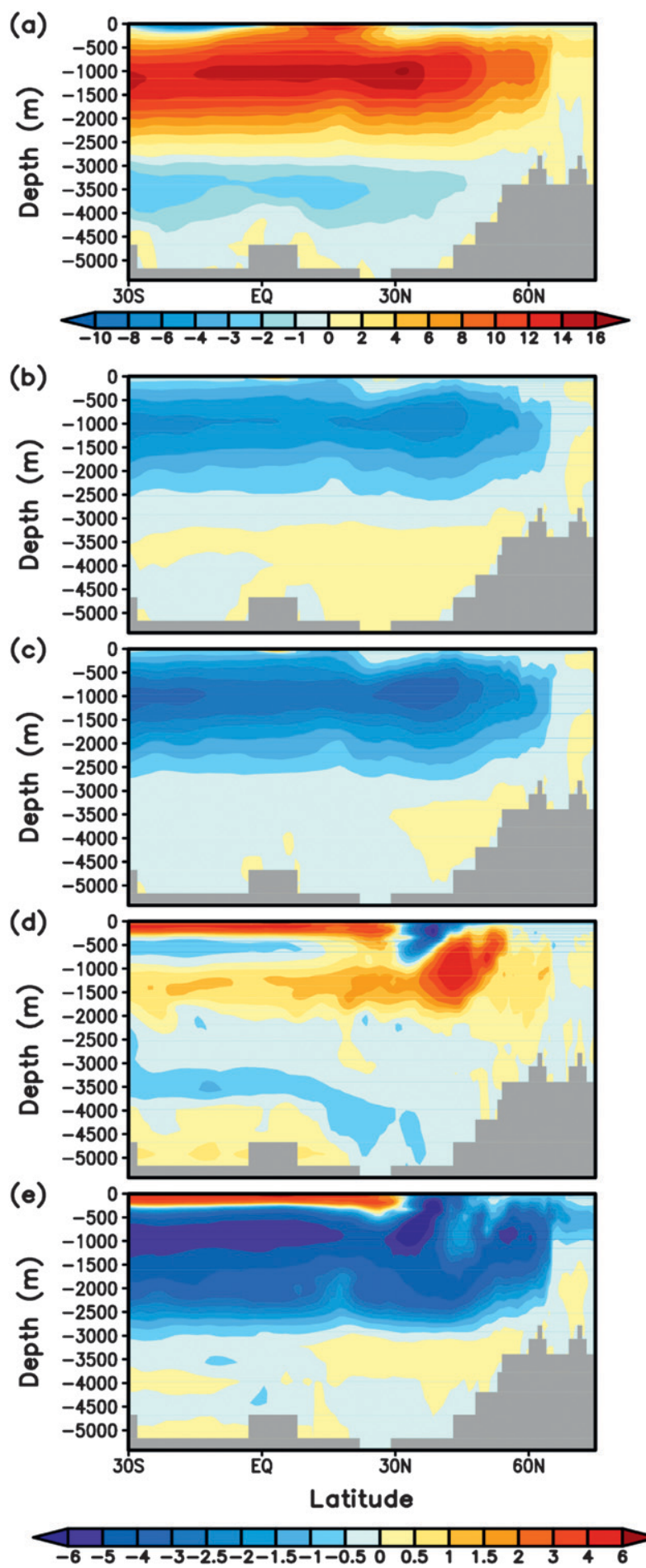

FIG. 4. Annual AMOC streamfunctions $\left(\mathrm{mm}\right.$ month $\left.^{-1}\right)$ in (a) CTL and their anomalies relative to CTL in (b) H6K, (c) H9KO, (d) H9KT, and (e) H9KM. 
this run, the prescribed LIS melting flux increased to $0.1 \mathrm{~Sv}$ to prevent any deep-water formation in the Labrador Sea.

\section{b. Periodicity of the AMO indices}

The AMO indices (Fig. 5) are constructed based on the simulated SSTs in a similar way following previous studies (e.g., Knight et al. 2005; Sutton and Hodson 2005; Dima and Lohmann 2007). Each index is calculated by averaging the annual mean SST over the region $0^{\circ}-60^{\circ} \mathrm{N}, 75^{\circ}-7.5^{\circ} \mathrm{W}$. All the indices are detrended and then normalized by subtracting each of them from their own mean values over the whole period. A roughly $0.4^{\circ} \mathrm{C}$ peak-to-peak oscillation can be obtained from an 11-yr running mean of each index. This is in good agreement with the observed AMO variation (e.g., Enfield et al. 2001).

Results from both instrumental and modeling studies (e.g., Knight et al. 2005; Dima and Lohmann 2007) have suggested that the engine for the AMO involves variations in the AMOC, which leads us to investigate the relation between the AMO and the AMOC in our simulations. The lag correlation between these two indices for each experiment is given in Fig. 5. The correlation coefficients reach the maximum with significant values when the AMOC leads the AMO by $1 \mathrm{yr}$ in all the experiments. However, considering the multidecadal time scale of the AMO variation, their relation is nearly in phase, suggesting the AMO is highly associated with the AMOC change. An interesting feature in the interannual AMOC indices is that much higher variation in H9KT and H9KM exists due to the cooling effect from the LIS and its melting, regardless of their mean values (Figs. $5 \mathrm{~d}, \mathrm{e}$ ). This is contrary to the notion that a weaker AMOC favors larger variability from a previous modeling study (Tziperman 1997).

Observed AMO indices typically have a 55-80-yr cycle (e.g., Enfield et al. 2001). To identify their periodicity in the simulation, we apply the multitaper method (MTM) spectral analysis (Park 1992) to the corresponding indices. As expected, a pronounced 55-80-yr cycle exists in all the AMO indices (Fig. 6). Meanwhile, variations in decadal and centennial time scale also can be found in each spectrum. The latter has been suggested to be associated with the centennial variation of the AMOC induced by Southern Hemisphere westerly winds (Wei et al. 2012). The prescribed forcing is kept constant during the integration. Thus, the simulated 5580 -yr cycle can provide further evidence that the periodicity of the AMO inferred from the instrumental data also exists in the simulation as indicated by previous studies (Delworth and Mann 2000; Knight et al. 2005), and is largely induced by the internal variability of the climate system. Our results also reveal that the AMO is a quasi-multidecadal oscillation independent of the background climate conditions. Nevertheless, the background climate conditions can modulate both the periodicity and magnitude of the AMO (Figs. 5 and 6).

To better investigate the influence of the background climate conditions on the periodicity of the AMO, we perform the wavelet spectral analysis (Fig. 6) using the time series shown in Fig. 5 to analyze the temporal modulation of the AMO periodicity. Similar with the MTM spectral analysis, all wavelet spectrums display a quasi-persistent 55-80-yr cycle. But interestingly, this cycle is more pronounced in some experiments, for example, CTL, H9KO, and H9KM (Figs. 5a,c,e). Combining these results with the mean climatology discussed in section 3a, however, there seems to be no direct explanation for this difference. It is also worth mentioning that significant spectral power overlapping the AMO variation band can be observed in the wavelet spectrums of the AMOC indices (not shown), as reflected by the covariance feature of these two indices (Fig. 5).

\section{c. Spatial patterns of the temperature and AMOC associated with the AMO}

The spatial patterns of the surface temperature associated with the AMO are illustrated by composite analyses of the surface air temperature with the corresponding AMO indices (Fig. 7). During the warm phase of the AMO, there is a quasi-monopolar temperature structure (Dima and Lohmann 2007) over the Atlantic Ocean, with dramatic warming in the north and slight cooling in the south. This quasi-monopolar temperature pattern is a robust feature of the AMO, as indicated by both observation (Enfield et al. 2001; Dima and Lohmann 2007) and modeling studies (Delworth and Mann 2000; Latif et al. 2004; Knight et al. 2005). Meanwhile, the North Pacific Ocean is also characterized by a general warming, which is affected through atmospheric teleconnections and local feedbacks (Dima and Lohmann 2007). A similar interdecadal Northern Hemispheric climate mode has been interpreted as an inherently coupled air-sea mode in an earlier study (Timmermann et al. 1998). It is worth noting that this feature of the AMO shows no significant difference during the Holocene.

Associated with the warm phase of the AMO, there is coherent strengthening of the AMOC streamfunction north of $30^{\circ} \mathrm{N}$ (Fig. 8). This in-phase relationship between the AMO and the AMOC reflects the high correlation of the AMO and AMOC indices (Fig. 5), further confirming that the AMO is potentially driven by the multidecadal variation of the AMOC. The slight weakening of the overturning around $60^{\circ} \mathrm{N}$ can 


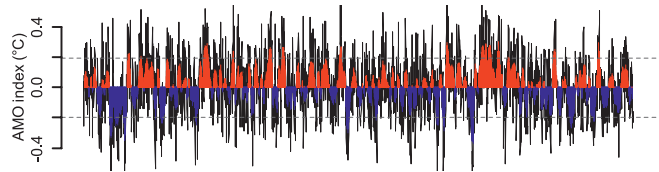

(a)
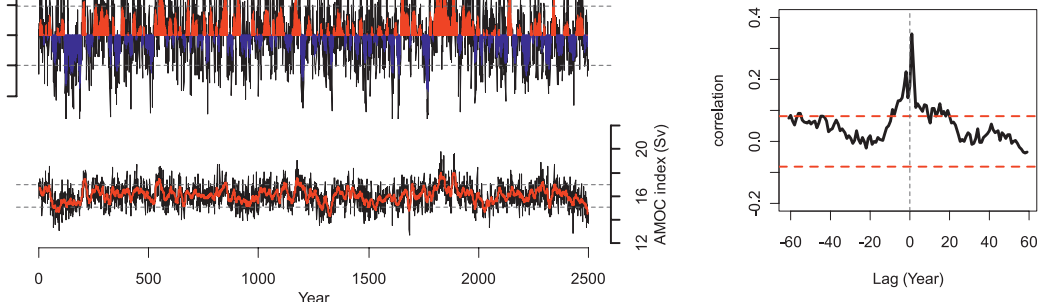

Lag (Year)

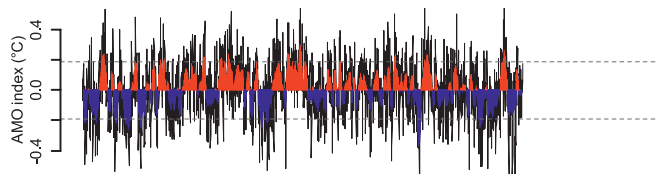

(b)
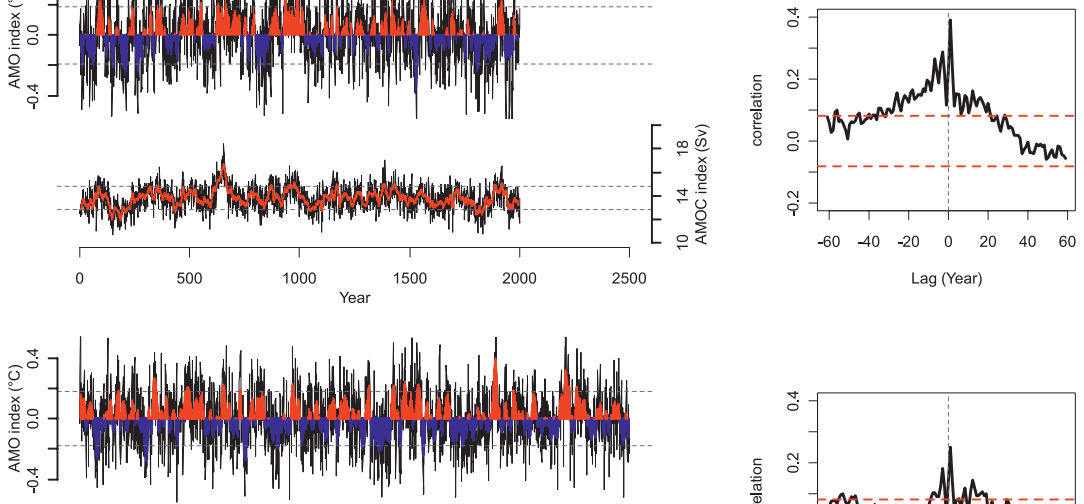

(c)
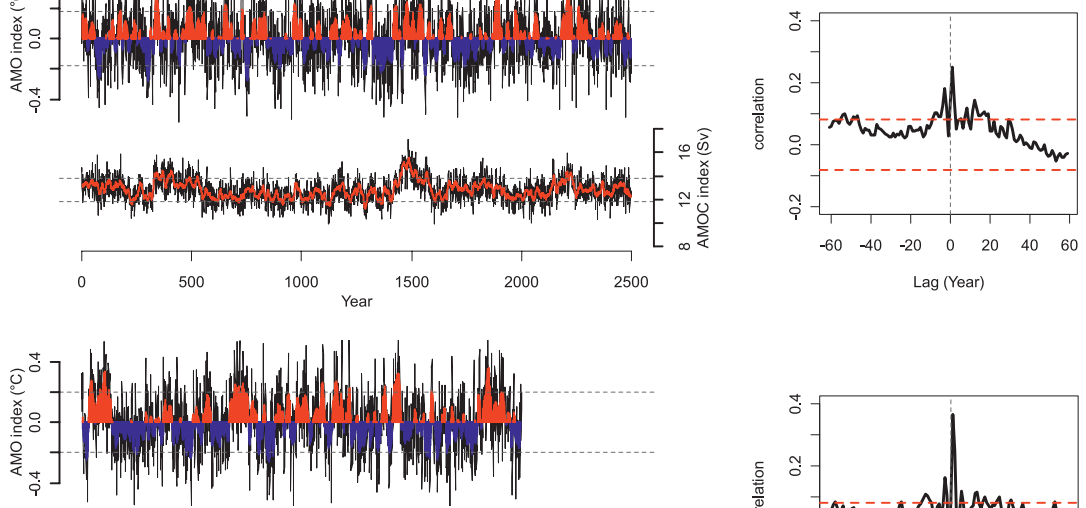

(d)
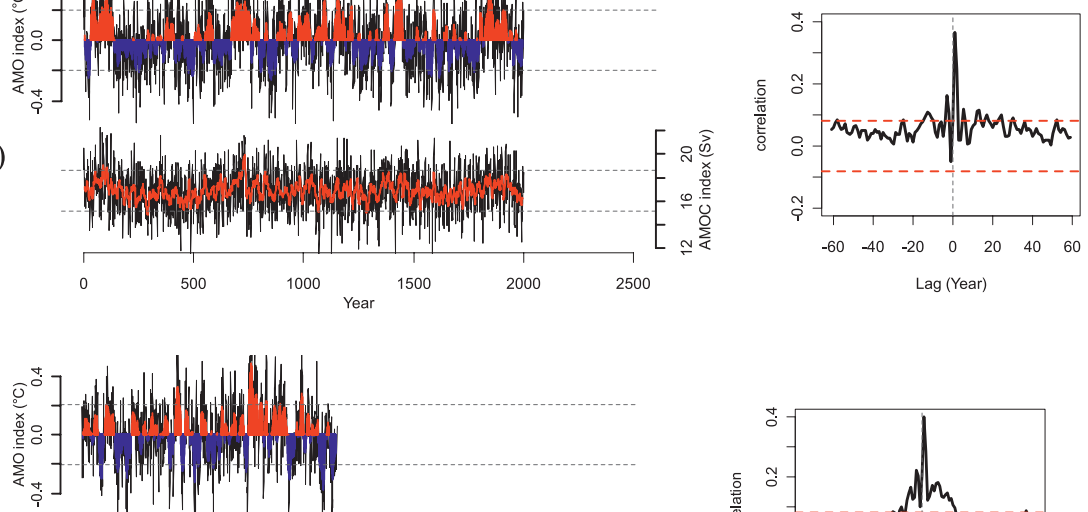

(e)
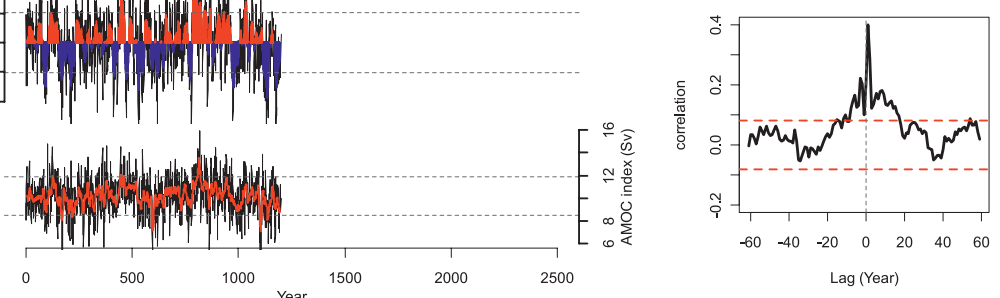

FIG. 5. (left) AMO indices $\left({ }^{\circ} \mathrm{C}\right.$ ) and the AMOC indices (Sv) for (a) CTL, (b) H6K, (c) H9KO, (d) H9KT, and (e) H9TM. AMO indices are constructed based on annual SST averaged over the region $0^{\circ}-60^{\circ} \mathrm{N}, 75^{\circ}-7.5^{\circ} \mathrm{W}$. Shading represents the $11-\mathrm{yr}$ running mean values. The AMOC indices are derived from the maximum meridional streamfunction at $1000-\mathrm{m}$ depth of $30^{\circ} \mathrm{N}$ in the Atlantic Ocean. Red solid lines indicate the mean and the 11-yr running mean values. Gray dashed lines represent $\pm 1 \sigma$ of the corresponding indices. (right) Lag correlation between the AMO indices and AMOC indices. Red dashed lines indicate the $99 \%$ significance level when 1000 degrees of freedom are selected concerning the autocorrelation in the time series. Positive lags (yr) indicate that the AMOC leads the AMO and vice versa. 
(a)

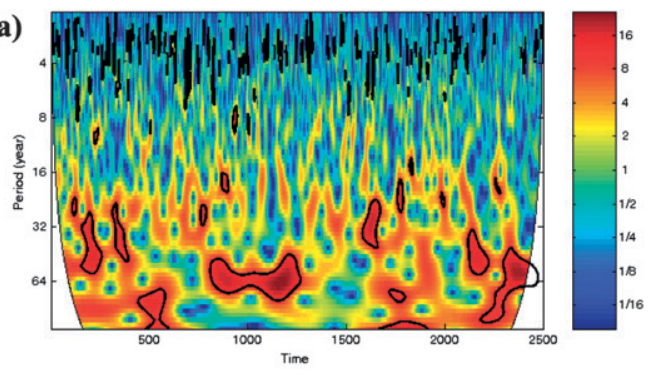

(b)

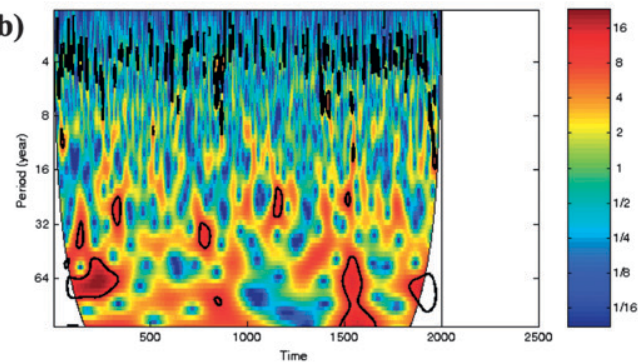

(c)

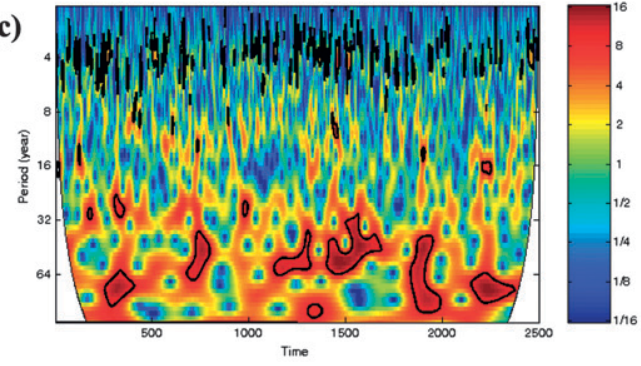

(d)
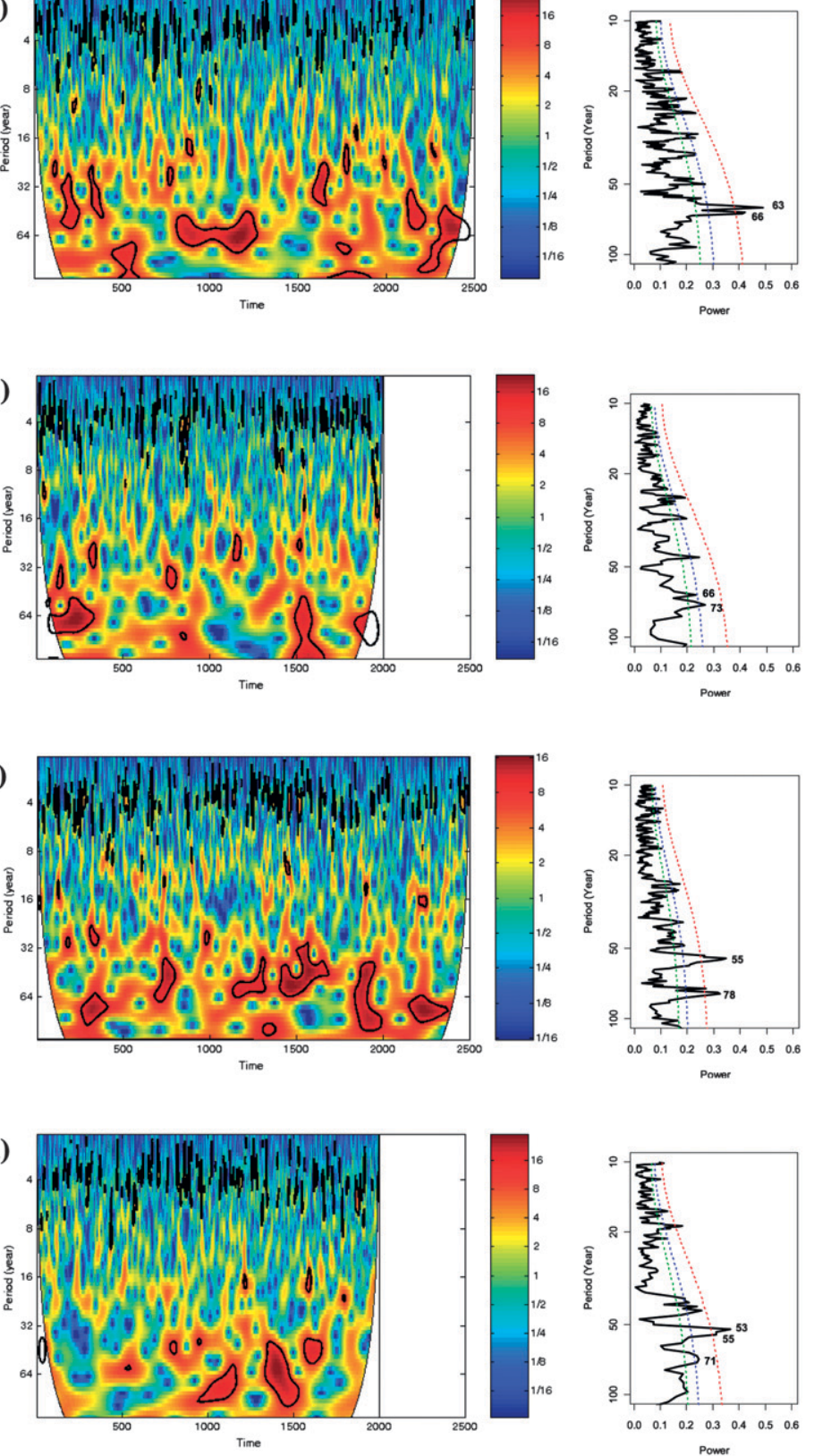

(e)

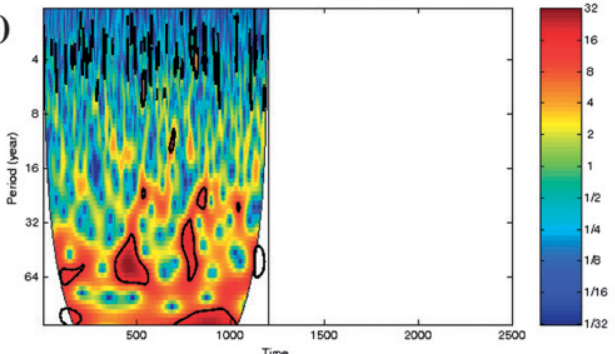

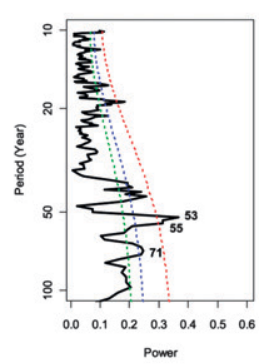

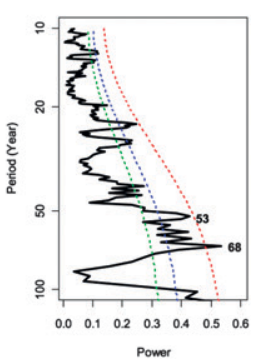

FIG. 6. (right) MTM spectral and (left) wavelet spectral analysis of the AMO indices for (a) CTL, (b) H6K, (c) H9KO, (d) H9KT, and (e) H9KM. In the MTM spectrum, the significance levels of $90 \%, 95 \%$, and $99 \%$ are plotted by green, blue, and red dotted lines, respectively. In the wavelet spectrum, the black circles indicate the $95 \%$ significant levels. 

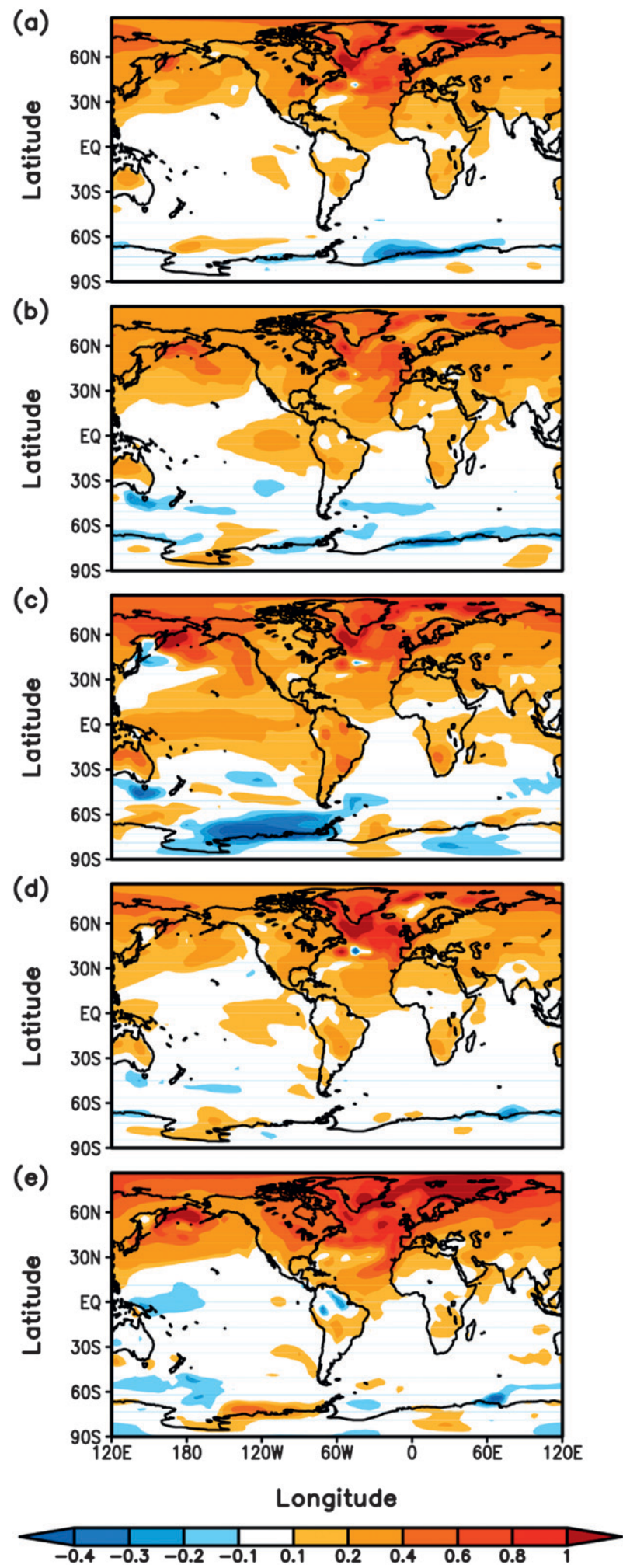

FIG. 7. Composite maps of annual surface temperature $\left({ }^{\circ} \mathrm{C}\right)$ with the AMO index for (a) CTL, (b) H6K, (c) H9KO, (d) H9KT, and (e) H9KM, respectively. Bandpass filter has been applied to both the indices and fields to assure only variations in multidecadal time scale are represented. A linear trend is also removed before the be linked to the shrinking of the sea ice coverage, resulting from the warming in the high latitudes (Fig. 9). The AMOC patterns demonstrate this common feature in all the experiments except that it shows a larger anomaly in H9TM (Fig. 8e), in which a relatively vigorous fluctuation of the AMOC exists (Fig. 5e). The most likely reason is that additional melt flux from the LIS in H9TM alters the background climate, causing a large-scale cooling in the North Atlantic Ocean (Fig. 2d). This cooling can lead to a more vigorous AMOC fluctuation, which, as a consequence, generates a larger AMO amplitude (Fig. 7e).

\section{d. Climate influence of the AMO}

During the warm phase of the AMO, not only the North Atlantic Ocean experiences a large-scale warming but also the warming can spread over the whole midhigh latitudes in the Northern Hemisphere (Fig. 7), consistent with previous observation and modeling studies (Knight et al. 2005). This warming shows a relatively stronger signal in H9KM (Fig. 7e), suggesting a possible stronger AMO influence associated with melting of the LIS. Over the low latitudes and the South Hemisphere mid-high latitudes, the AMO influence is not significant except for slightly warming over the land areas, that is, part of South America, North Australia, and part of Africa (Fig. 7).

The associated sea ice change (Fig. 9) is consistent with the change in the surface temperature (Fig. 7). During the warm phase of AMO, the warming in the Northern Hemisphere high latitudes leads to melting of sea ice. Decrease of the sea ice fraction has the maximum in Barents Sea, where the strongest warming occurs due to the heat transport by the ocean current. The feature in the Southern Ocean is not clear. Both positive and negative sea ice anomalies exist in this latitude band, suggesting a different climate response to the AMO in this region and possible difficulty in the proxy data from this region to reconstruct the past AMO signal.

The maximum positive anomaly in precipitation associated with the AMO warm period is located over the North Atlantic low latitudes, with pronounced wetter

composite analysis. Composite maps shown here are calculated by subtracting the fields that have higher than one standard deviation of the mean from those with lower than one standard deviation with respect to the indices. Here, anomalies with a significance level higher than $95 \%$ using a Student's $t$ test are considered before plotting. 

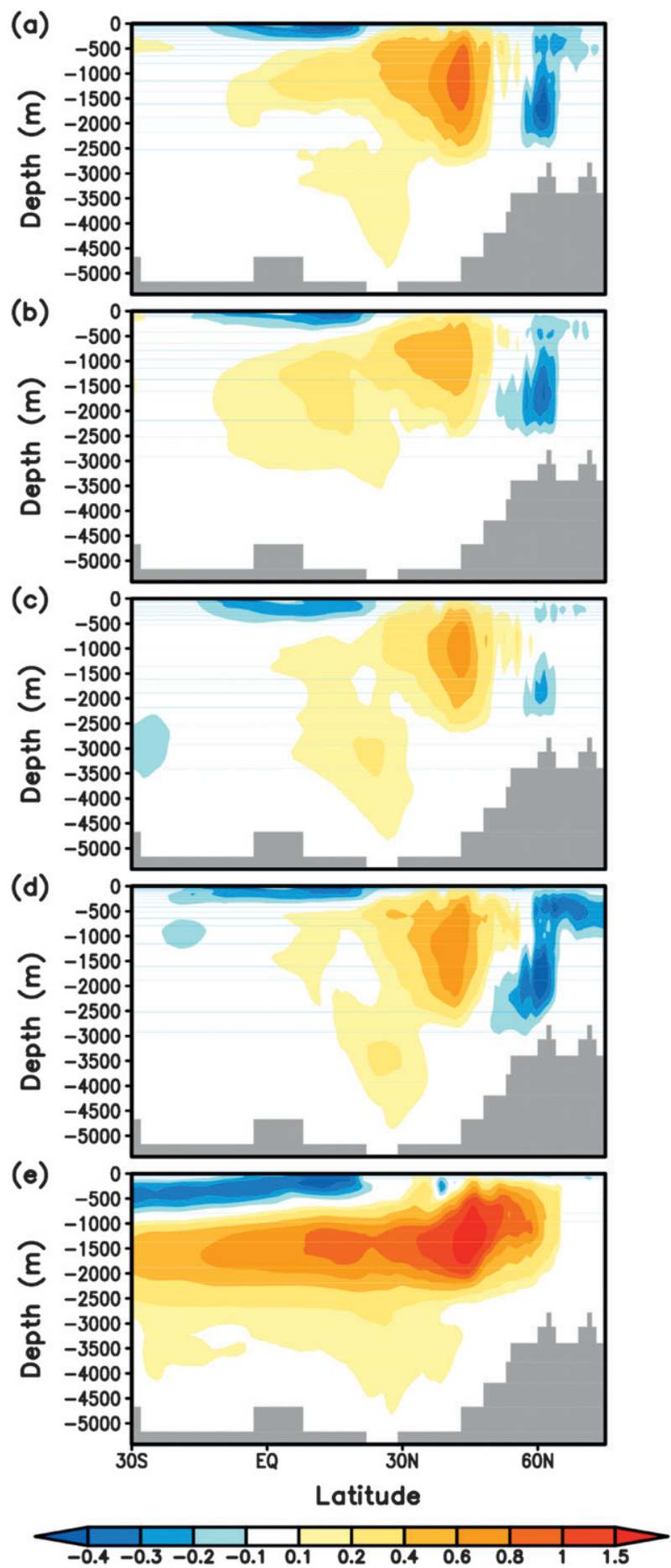

FIG. 8. As in Fig. 7, but for annual AMOC streamfunctions (Sv).

conditions (Fig. 10). Moderate anomalies include more rainfall over the Sahel, drought conditions in the North American east coastal areas, wetter conditions in $\mathrm{Eu}-$ rope, and less precipitation in Brazil (Fig. 10), all of which are consistent with previous findings (Sutton and
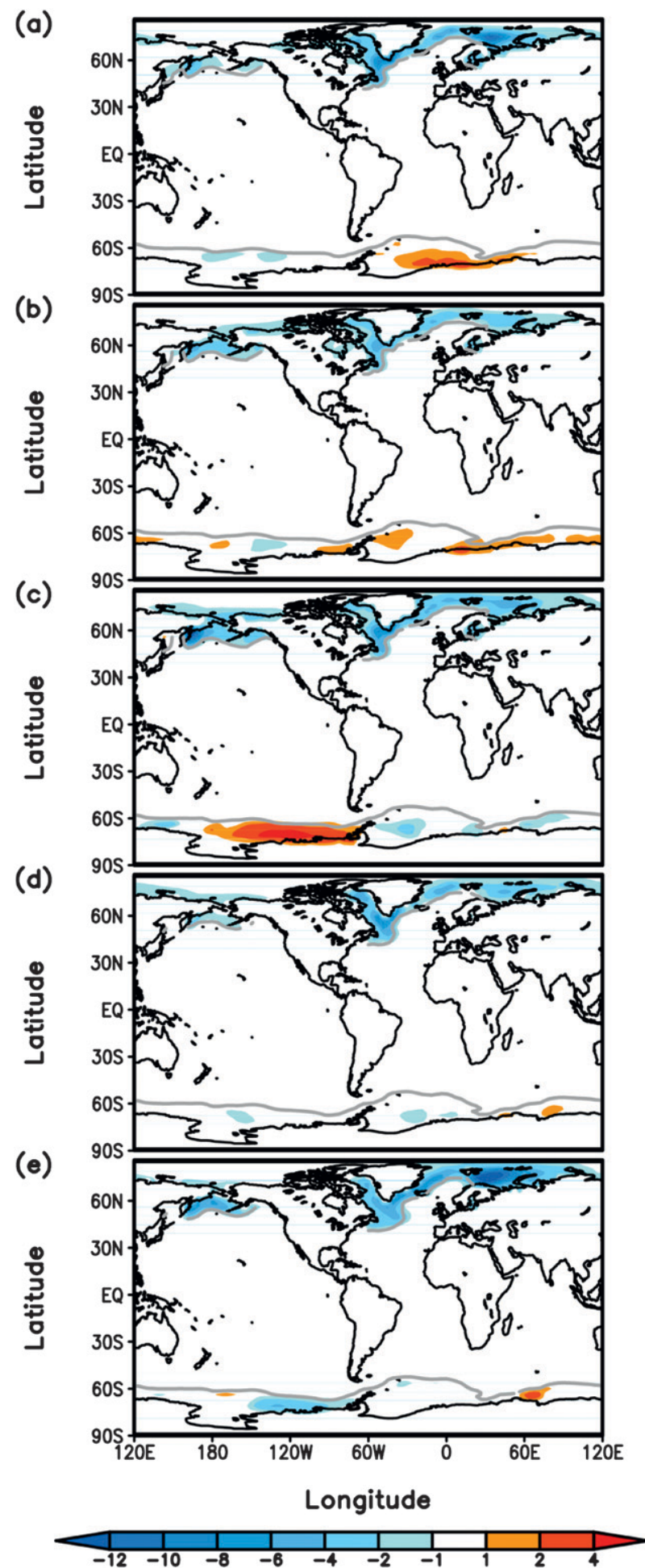

FIG. 9. As in Fig. 7, but for annual sea ice fraction (\%). Gray solid lines indicate the boundary of maximum sea ice coverage in each experiment. 

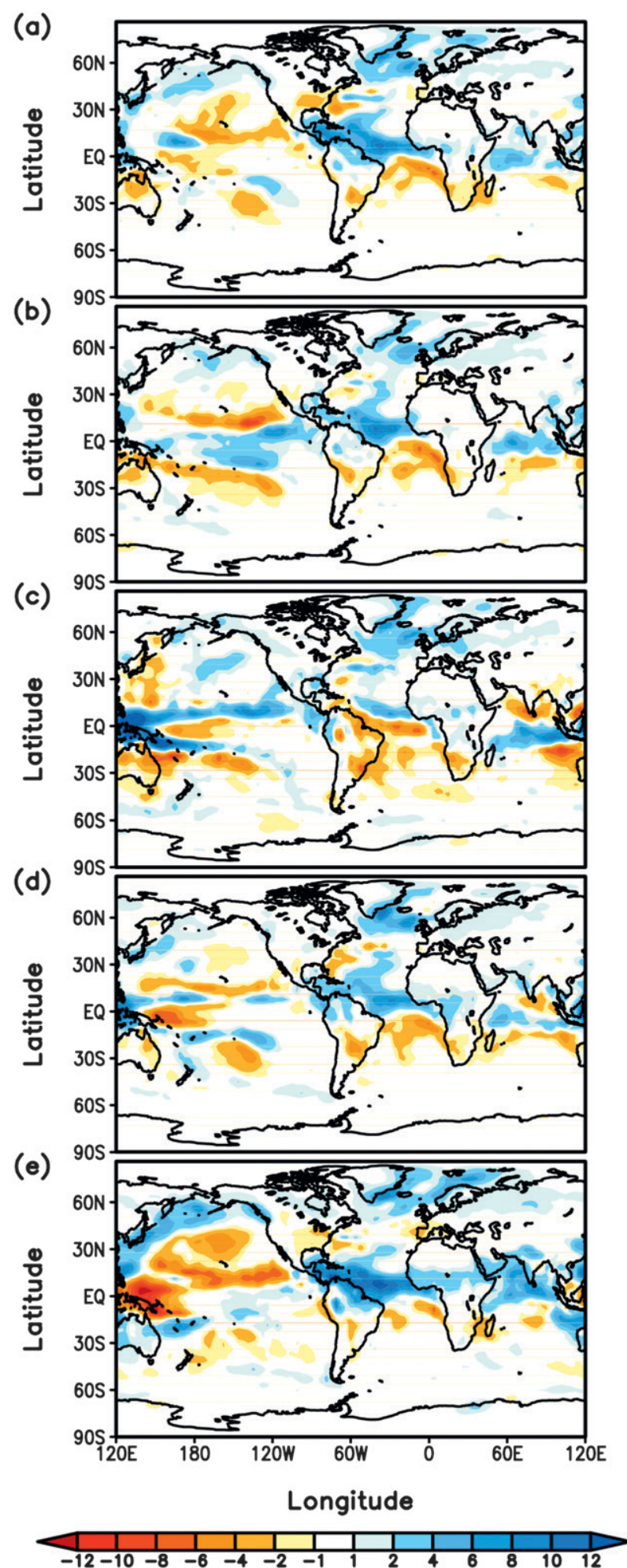

FIG. 10. As in Fig. 7, but for annual precipitation ( $\left.\mathrm{mm} \mathrm{month}^{-1}\right)$.
Hodson 2005; Knight et al. 2006). This evidence further supports that the Atlantic Ocean plays the dominant role on the multidecadal time scale climate change in the regions mentioned above (Sutton and Hodson 2005). It is worth noting that there are also considerable precipitation anomalies over the western Pacific Ocean, especially in the early Holocene runs (Figs. 10c-e). This can be directly linked to the temperature anomalies between two AMO phases (Figs. 7c-e), with more convection under warmer conditions and vice versa. Furthermore, there are strong drying conditions over the western Pacific Ocean in the early Holocene runs (Figs. 3c-e). It is likely that the drying gives rise to a more sensitive character of this region to the AMO change.

\section{Discussion and conclusions}

The simulated AMO indices under present-day and Holocene climate conditions exhibit a quasi-multidecadal periodicity, consistent with the 55-80-yr cycle of the AMO found in the observation data (Schlesinger and Ramankutty 1994; Kerr 2000). Such periodicities exist throughout the Holocene, although it is not continuous in each simulation. This intermittent feature of the climate system has also been documented by the proxy data in the last $6000 \mathrm{yr}$ (Moberg et al. 2005; Wanner et al. 2008; Wirtz et al. 2010). There is no external forcing change during the integration; therefore, the AMO in the model is internally generated. This is consistent with previous proxy AMO reconstruction (Lohmann et al. 2004; Knudsen et al. 2011), suggesting that the AMO is dominated by the internal variability of the climate system but not necessarily forced by periodic solar activities.

Concerning the forcing mechanism of the AMO, the most common believed physical process involves the variation of the AMOC. Although a full understanding of such a process is beyond the scope of this study, our results show there is a significantly positive correlation between the AMO and the AMOC.

A warm phase of the AMO is associated with an intensified AMOC. It accompanies a hemispheric-scale warming in the Northern Hemisphere, with the maximum warming over the North Atlantic Ocean and part of the Arctic Ocean, which reduces the sea ice there. Such a warming favors more convection and thus more precipitation over most of the North Atlantic Ocean, especially enhancing the Atlantic ITCZ. This finding supports the suggestion that the Atlantic warm pool acts as a link between the AMO and tropical cyclone activity, which provides the fuel for more moisture convection in this region (Wang et al. 2008). 
The climate influence of the AMO demonstrates that the basinwide warming is a common feature during the Holocene despite the climate background conditions, which further reveals that the AMO is an internal variability of the climate system. However, we argue that the climate influence of the AMO might be amplified by a vigorous background climate condition, which can generate a larger fluctuation of the AMOC and thus a higher magnitude of the AMO. It has been supported by a previous study (Knudsen et al. 2011) that suggests that the response to the AMO can be modulated by orbitally induced shifts in large-scale ocean-atmosphere circulation. This has potential application to the deglaciation periods, when stronger AMOC fluctuation occurs, as well as the future climate, given the most likely increasing in melting of the Greenland Ice Sheet (e.g., Fettweis et al.2007). Thus, it is conceivable that the AMO influence could be more significant under ongoing global warming, which could either amplify or mask the anthropogenic warming in the future.

Acknowledgments. We appreciate three reviewers for their constructive comments. This work is funded by Deutsche Forschungsgemeinschaft (DFG) under the Special Priority Programme INTERDYNAMIK. It is also a contribution to the "Earth System Science Research School (ESSReS)," an initiative of the Helmholtz Association of German Research Centres (HGF) at the Alfred Wegener Institute for Polar and Marine Research.

\section{REFERENCES}

Berger, A. L., 1978: Long-term variations of daily insolation and quaternary climatic changes. J. Atmos. Sci., 35, 2362-2367.

Braconnot, P., and Coauthors, 2007: Results of PMIP2 coupled simulations of the Mid-Holocene and Last Glacial Maximum Part 1: Experiments and large-scale features. Climate Past, 3, 261-277.

Brook, E. J., S. Harder, J. Severinghaus, E. J. Steig, and C. M. Sucher, 2000: On the origin and timing of rapid changes in atmospheric methane during the last glacial period. Global Biogeochem. Cycles, 14, 559-572.

Chylek, P., C. K. Folland, G. Lesins, M. K. Dubey, and M. Wang, 2009: Arctic air temperature change amplification and the Atlantic multidecadal oscillation. Geophys. Res. Lett., 36, L14801, doi:10.1029/2009GL038777.

Crucifix, M., P. Braconnot, S. P. Harrison, and B. Otto-Bliesner, 2005: Second phase of Paleoclimate Modelling Intercomparison Project. Eos, Trans. Amer. Geophys. Union, 86, 264, doi:10.1029/ 2005EO280003.

Delworth, T. L., and M. E. Mann, 2000: Observed and simulated multidecadal variability in the Northern Hemisphere. Climate Dyn., 16, 661-676.

Dima, M., and G. Lohmann, 2007: A hemispheric mechanism for the Atlantic multidecadal oscillation. J. Climate, 20, 27062719.
Enfield, D., A. Mestas-Nunez, and P. Trimble, 2001: The Atlantic multidecadal oscillation and its relation to rainfall and river flows in the continental U.S. Geophys. Res. Lett., 28, 2077 2080.

Feng, S., Q. Hu, and R. J. Oglesby, 2009: AMO-like variations of Holocene sea surface temperatures in the North Atlantic Ocean. Climate Past Discuss., 5, 2465-2496.

,-- , and -2011 : Influence of Atlantic sea surface temperatures on persistent drought in North America. Climate Dyn., 37, 569-586, doi:10.1007/s00382-010-0835-x.

Fettweis, X., J.-P. van Ypersele, H. Gallée, F. Lefebre, and W. Lefebvre, 2007: The 1979-2005 Greenland Ice Sheet melt extent from passive microwave data using an improved version of the melt retrieval XPGR algorithm. Geophys. Res. Lett., 34, L05502, doi:10.1029/2006GL028787.

Fischer, N., and J. Jungclaus, 2009: Effects of orbital forcing on atmosphere and ocean heat transports in Holocene and Eemian climate simulations with a comprehensive earth system model. Climate Past Discuss., 5, 2311-2341.

Folland, C. K., T. N. Palmer, and D. E. Parker, 1986: Sahel rainfall and worldwide sea temperatures, 1901-85. Nature, 320, 602607.

_ , A. W. Colman, D. P. Rowell, and M. K. Davey, 2001: Predictability of Northeast Brazil rainfall and real-time forecast skill, 1987-98. J. Climate, 14, 1937-1958.

Ganachaud, A., and C. Wunsch, 2000: Improved estimates of global ocean circulation, heat transport and mixing from hydrographic data. Nature, 408, 453-457.

Gent, P., J. Willebrand, T. McDougall, and J. McWilliams, 1995: Parameterizing eddy-induced tracer transports in ocean circulation models. J. Phys. Oceanogr., 25, 463-474.

Gibson, J. K., P. Kållberg, S. Uppala, A. Hernandez, A. Nomura, and E. Serrano, 1999: ERA-15 description (version 2). ECMWF Re-Analysis Project Rep. Series 1, 84 pp.

Giry, C., T. Felis, M. Kölling, D. Scholz, W. Wei, and S. Scheffers, 2012: Mid- to late Holocene changes in tropical Atlantic temperature seasonality and interannual to multidecadal variability documented in southern Caribbean corals. Earth Planet. Sci. Lett., 331-332, 187-200, doi:10.1016/j.epsl.2012.03.019.

Goldenberg, S. B., C. W. Landsea, A. M. Mestas-Nuñez, and W. M. Gray, 2001: The recent increase in Atlantic hurricane activity: Causes and implications. Science, 293, 474, doi: 10.1126/science. 1060040.

Gray, S. T., L. J. Graumlich, J. L. Betancourt, and G. T. Pederson, 2004: A tree-ring based reconstruction of the Atlantic multidecadal oscillation since 1567 AD. Geophys. Res. Lett., 31, L12205, doi:10.1029/2004GL019932.

Grosfeld, K., G. Lohmann, N. Rimbu, K. Fraedrich, and F. Lunkeit, 2007: Atmospheric multidecadal variations in the North Atlantic realm: Proxy data, observations, and atmospheric circulation model studies. Climate Past, 3, 39-50.

Hagemann, S., and L. Dümenil, 1997: A parametrization of the lateral waterflow for the global scale. Climate Dyn., 14, 17-31. , and L. D. Gates, 2003: Improving a subgrid runoff parameterization scheme for climate models by the use of high resolution data derived from satellite observations. Climate Dyn., 21, 349-359.

Haug, G. H., K. A. Hughen, D. M. Sigman, L. C. Peterson, and U. Röhl, 2001: Southward migration of the intertropical convergence zone through the Holocene. Science, 293, 1304. 
Herold, M., and G. Lohmann, 2009: Eemian tropical and subtropical African moisture transport: An isotope modelling study. Climate Dyn., 33, 1075-1088.

Heslop, D., and A. Paul, 2010: Can oceanic paleothermometers reconstruct the Atlantic multidecadal oscillation? Climate Past Discuss., 6, 2177-2197.

Hetzinger, S., M. Pfeiffer, W.-C. Dullo, N. Keenlyside, M. Latif, and J. Zinke, 2008: Caribbean coral tracks Atlantic multidecadal oscillation and past hurricane activity. Geology, 36, 11-14, doi:10.1130/G24321A.1.

Hibler, W., III, 1979: A dynamic thermodynamic sea ice model. J. Phys. Oceanogr., 9, 815-846.

$\mathrm{Hu}$, Q., and S. Feng, 2008: Variation of the North American summer monsoon regimes and the Atlantic multidecadal oscillation. J. Climate, 21, 2371-2383.

Indermühle, A., and Coauthors, 1999: Holocene carbon-cycle dynamics based on $\mathrm{CO}_{2}$ trapped in ice at Taylor Dome, Antarctica. Nature, 398, 121-126, doi:10.1038/18158.

Kerr, R. A., 2000: A North Atlantic climate pacemaker for the centuries. Science, 288, 1984-1985.

Knight, J. R., R. J. Allan, C. K. Folland, M. Vellinga, and M. E. Mann, 2005: A signature of persistent natural thermohaline circulation cycles in observed climate. Geophys. Res. Lett., 32, L20708, doi:10.1029/2005GL024233.

- C. K. Folland, and A. A. Scaife, 2006: Climate impacts of the Atlantic multidecadal oscillation. Geophys. Res. Lett., 33, L17706, doi:10.1029/2006GL026242.

Knudsen, M. F., M. S. Seidenkrantz, B. H. Jacobsen, and A. Kuijpers, 2011: Tracking the Atlantic multidecadal oscillation through the last 8,000 years. Nature Commun., 2, 178.

Koutavas, A., P. B. deMenocal, G. C. Olive, and J. Lynch-Stieglitz, 2006: Mid-Holocene El Nino-Southern Oscillation (ENSO) attenuation revealed by individual foraminifera in eastern tropical Pacific sediments. Geology, 34, 993-996, doi:10.1130/ G22810A.1.

Kutzbach, J., and Z. Liu, 1997: Response of the African monsoon to orbital forcing and ocean feedbacks in the middle Holocene. Science, 278, 440-443.

Latif, M., and Coauthors, 2004: Reconstructing, monitoring, and predicting multidecadal-scale changes in the North Atlantic thermohaline circulation with sea surface temperature. J. Climate, 17, 1605-1614.

Licciardi, J. M., J. T. Teller, and P. U. Clark, 1999: Freshwater routing by the Laurentide Ice Sheet during the last deglaciation. Mechanisms of Global Climate Change at Millennial Time Scales, Geophys. Monogr., Vol. 112, Amer. Geophys. Union, 177-201.

Lohmann, G., N. Rimbu, and M. Dima, 2004: Climate signature of solar irradiance variations: Analysis of long-term instrumental, historical, and proxy data. Int. J. Climatol., 24, 1045-1056.

Lu, R., B. Dong, and H. Ding, 2006: Impact of the Atlantic multidecadal oscillation on the Asian summer monsoon. Geophys. Res. Lett., 33, L24701, doi:10.1029/2006GL027655.

Mann, M. E., J. Park, and R. Bradley, 1995: Global interdecadal and century-scale climate oscillations during the past five centuries. Nature, 378, 266-269.

Marsland, S., H. Haak, J. Jungclaus, M. Latif, and F. Röske, 2003: The Max-Planck-Institute global ocean/sea ice model with orthogonal curvilinear coordinates. Ocean Modell., 5, 91-127.

McCabe, G. J., M. A. Palecki, and J. L. Betancourt, 2004: Pacific and Atlantic Ocean influences on multidecadal drought frequency in the United States. Proc. Natl. Acad. Sci. USA, 101, 4136.
Moberg, A., D. M. Sonechkin, K. Holmgren, N. M. Datsenko, and W. Karlén, 2005: Highly variable Northern Hemisphere temperatures reconstructed from low- and high-resolution proxy data. Nature, 433, 613-617.

Oglesby, R. J., S. Feng, Q. Hu, and C. Rowe, 2011: Medieval drought in North America: The role of the Atlantic multidecadal oscillation. PAGES News, No. 19, PAGES International Project Office, Bern, Switzerland, 18-20.

Park, J., 1992: Envelope estimation for quasi-periodic geophysical signals in noise: A multitaper approach. Statistics in the Environmental and Earth Sciences: New Developments in Theory and Practice, A. T. Walden and P. Guttorp, Eds., Hodder Education Publishers, 189-219.

Peltier, W. R., 2004: Global glacial isostasy and the surface of the ice-age earth: The ICE-5G (VM2) model and GRACE. Annu. Rev. Earth Planet. Sci., 32, 111-149.

Poore, R. Z., K. L. DeLong, J. N. Richey, and T. M. Quinn, 2009: Evidence of multidecadal climate variability and the Atlantic multidecadal oscillation from a Gulf of Mexico sea-surface temperature-proxy record. Geo-Mar. Lett., 29, 477-484.

Raddatz, T., and Coauthors, 2007: Will the tropical land biosphere dominate the climate-carbon cycle feedback during the twenty-first century? Climate Dyn., 29, 565-574.

Renssen, H., H. Goosse, X. Crosta, and D. M. Roche, 2010: Early Holocene Laurentide Ice Sheet deglaciation causes cooling in the high-latitude Southern Hemisphere through oceanic teleconnection. Paleoceanography, 25, PA3204, doi:10.1029/ 2009PA001854.

Roeckner, E., and Coauthors, 2003: The atmospheric general circulation model ECHAM5. Part I: Model description. Planck Institute for Meteorology Rep. 349, $131 \mathrm{pp}$.

— , and Coauthors, 2004: The atmospheric general circulation model ECHAM5. Part II: Sensitivity of simulated climate to horizontal and vertical resolution. Max Planck Institute for Meteorology Rep. 354, 60 pp.

Rowell, D. P., C. K. Folland, K. Maskell, and M. N. Ward, 1995: Variability of summer rainfall over tropical North Africa (1906-92): Observations and modelling. Quart. J. Roy. Meteor. Soc., 121, 669-704.

Schlesinger, M. E., and N. Ramankutty, 1994: An oscillation in the global climate system of period 65-70 years. Nature, 367, 723-726.

Sowers, T., R. B. Alley, and J. Jubenville, 2003: Ice core records of atmospheric $\mathrm{N}_{2} \mathrm{O}$ covering the last 106,000 years. Science, $\mathbf{3 0 1}$, 945-948.

Sutton, R. T., and D. L. R. Hodson, 2005: Atlantic Ocean forcing of North American and European summer climate. Science, 309, $115-118$.

Timmermann, A., M. Latif, R. Voss, and A. Grötzner, 1998: Northern Hemispheric interdecadal variability: A coupled air-sea mode. J. Climate, 11, 1906-1931.

Tziperman, E., 1997: Inherently unstable climate behaviour due to weak thermohaline ocean circulation. Nature, 386, 592-595.

Valcke, S., Ed., 2006: OASIS3 user guide (prism_2-5). CERFACS PRISM Support Initiative Rep. 3, 64 pp.

Wang, C., and S. Dong, 2010: Is the basin-wide warming in the North Atlantic Ocean related to atmospheric carbon dioxide and global warming? Geophys. Res. Lett., 37, L08707, doi:10.1029/2010GL042743.

, S.-K. Lee, and D. B. Enfield, 2008: Atlantic warm pool acting as a link between Atlantic multidecadal oscillation and Atlantic tropical cyclone activity. Geochem. Geophys. Geosyst., 9, Q05V03, doi:10.1029/2007GC001809. 
Wanner, H., and Coauthors, 2008: Mid-to late Holocene climate change: An overview. Quat. Sci. Rev., 27, 1791-1828.

Wei, W., G. Lohmann, and M. Dima, 2012: Distinct modes of internal variability in the global meridional overturning circulation associated with the Southern Hemisphere westerly winds. J. Phys. Oceanogr., 42, 785-801.

Wirtz, K., G. Lohmann, K. Bernhardt, and C. Lemmen, 2010: MidHolocene regional reorganization of climate variability: Analyses of proxy data in the frequency domain. Palaeogeogr. Palaeoclimatol. Palaeoecol., 298, 189-200.
Zhang, R., and T. L. Delworth, 2006: Impact of Atlantic multidecadal oscillations on India/Sahel rainfall and Atlantic hurricanes. Geophys. Res. Lett., 33, L17712, doi:10.1029/ 2006 GL026267.

— tion on North Pacific climate variability. Geophys. Res. Lett., 34, L23708, doi:10.1029/2007GL031601.

Zhao, Y., and Coauthors, 2005: A multi-model analysis of the role of the ocean on the African and Indian monsoon during the mid-Holocene. Climate Dyn., 25, 777-800. 